\title{
Probing Nanoscale Morphology of PS/PMMA/CdS \& PS/PVC/CdS Polymeric Nanocomposites through Small Angle X-Ray Scattering Analysis
}

\author{
Vishal Mathur ${ }^{1,2 *}$, Kananbala Sharma ${ }^{2}$ \\ ${ }^{1}$ Faculty of Science \& Technology, The ICFAI University, Jaipur, India \\ ${ }^{2}$ Semi-Conductor \& Polymer Science Laboratory, Department of Physics, University of Rajasthan, Jaipur, India \\ Email: ${ }^{*}$ wishalmathur@gmail.com
}

Received 15 August 2014; revised 13 September 2014; accepted 9 October 2014

Copyright (C) 2014 by authors and Scientific Research Publishing Inc.

This work is licensed under the Creative Commons Attribution International License (CC BY). http://creativecommons.org/licenses/by/4.0/

\section{(c) (i) Open Access}

\begin{abstract}
Polymeric nanocomposites of PS/PMMA/CdS and PS/PVC/CdS samples have been synthesized through dispersion solution casting technique. The nanoparrticles of CdS were prepared by simple chemical method using $\mathrm{CdCl}_{2}$ and $\mathrm{H}_{2} \mathrm{~S}$ gas produced from thiourea. The nanoscale morphology of the prepared polymeric nanocomposite samples is probed through small angle $\mathrm{X}$-ray scattering (SAXS). The SAXS study reveals that CdS nanoparticles take place at voids position in the respective plymer blend matrix and exhibit their nano nature with very little tendency to agglomerates.
\end{abstract}

\section{Keywords}

Small Angle X-Ray Scattering, Polymer Nanocomposite, CdS Nanoparticles, Polymer Characterization

\section{Introduction}

One of the significant aspirations for nanoscale synthesis is the production of structures that accomplish monodispersity, stability, and crystallinity with a predictable morphology. The cadmium sulphide (CdS) is a technologically useful material, as many devices based on CdS, including sensors that have been come up in the recent years. The thin film cadmium sulphide solar cell has for several years been considered to be a promising alternative to the more widely used silicon devices [1]. The assorted technological applications of CdS nanocomposites

\footnotetext{
*Corresponding author.
}

How to cite this paper: Mathur, V. and Sharma, K. (2014) Probing Nanoscale Morphology of PS/PMMA/CdS \& PS/PVC/CdS Polymeric Nanocomposites through Small Angle X-Ray Scattering Analysis. Modern Instrumentation, 3, 25-28. 
comprise biological labeling and diagnostics, LED’s, electro-luminescent devices, photovoltaic devices, lasers and single electrode transistors [2] [3]. The key problems in this field entail synthesis, functionalization of the nanoparticles and dispersion in a polymer matrix. Among various polymers, polystyrene (PS), poly vinylchloride (PVC) and poly methyl mertha acraylate poly methyl methacrylate (PMMA) stand as primary industrial polymeric materials. Polymer blends of these constitute polymers have been extensively used in the industry because of their ability to combine in a unique material the properties of their components, at a relatively low cost when compared to the development of a new polymer [4]-[6].

Further, the properties of nanocomposite materials can be tailored by selecting particle size, size distribution or shape of particles [7]. The particle size plays a crucial role in nanoparticle properties and therefore an essential task in property characterization of nanoparticles is particle sizing. The particle size and size distribution of nanoparticles can be determined using numerous commercially available instruments [8]. This paper describes an investigation of small-angle X-ray scattering as one of the best possible techniques for probing nanoscale morphology and particle size of PS/PMMA/CdS and PS/PVC/CdS nanocomposites samples through small angle $\mathrm{X}$-ray scattering technique.

\section{Experimental}

\subsection{Material Preparation}

Firstly the CdS nanoparticles have been prepared by simple chemical method using $\mathrm{CdCl}_{2}$ and $\mathrm{H}_{2} \mathrm{~S}$ gas produced from thiourea. The polymer blend matrices are achieved by mixing constitutes polymer in equal proportion in the tetrahydrofuran (T.H.F.) solvent. Then, $4 \%$ wt CdS nanofiller particles were dispersed in repective PS/PVC and PS/PMMA polymer matrices during the solution casting process. These solutions was then stirred with the help of sonicator for about 6 hours and then poured into flat-bottomed petri dishes to form film with a thickness of $\sim 0.04 \mathrm{~mm}$. The solvent is allowed to evaporate slowly over a period of 24 hours in dry atmosphere. The so obtained film was then peeled off and dried in vacuum at $50^{\circ} \mathrm{C}$ [9] [10].

\subsection{Small Angle X-Ray Scattering (SAXS) Technique}

Small-angle X-ray scattering (SAXS) is a powerful tool which provides information about the morphology of a polymer matrix on length scales from a few nanometers to several micrometers. The electron-density fluctuations within the nanocomposite sample cause the scattering of incident X-rays, which leads to characteristic patterns. The scattering intensity, $I(q)$, is usually shown as a function of the scattering vector $(q)$

$$
q=(4 \pi / \lambda) \cdot \sin (\theta / 2)
$$

where, $\theta$ and $\lambda$ correspond to the scattering angle and the wavelength of the incident X-rays, respectively [11].

The present the small angle X-ray scattering analysis have been carried out on an X'Pert Pro MPD system to investigate the size of the CdS-nanoparticles within nanocomposite samples.

\section{Results and Discussion}

\section{Small angle $X$-ray scattering analysis}

Figure 1 shows the X-ray scattering intensity curve as a function of small scattering angle $(2 \theta)$ within $0^{\circ}$ to $5.5^{\circ}$ angular scale range, for respective PS/PMMA/CdS and PS/PVC/CdS nanocomposite samples.

It is observed that SAXS pattern of nano CdS dispersed polymeric blend matrices show higher scattering intensity as compared to their counterpart without CdS dispersed samples. This is attributed due to the fact that the CdS nanoparticle takes position at the voids site in respective blend matrix. There they act as independent scattering centers and contributes by enhancing scattering intensity in the respective nanocomposites's SAXS pattern.

The background scattering intensity (without CdS embedded polymeric phase) is being subtracted from scattering intensity of CdS embedded polymeric nanocomposite phases with the help of EasySAXS software. The software makes automatic calculations for preparing characterizations reports. SAXS characterization reports of respective nanocomposites are used for elucidating the shape and size of CdS nano-crystals. The so obtain particle size distribution curves from EasySAXS software for respective nanocomposite samples is shown in Figure 2. The particle size distribution reports of respective nanocomposites suggest that the distribution is well approximated by a Gaussian. 
Table 1 shows the summary of analysis obtained from these particle size distribution curves. It is observed that all of these curves approximately centered at $\mathrm{R}=4.1 \mathrm{~nm}$ and it means that the most frequent radius of CdS nanoparticles is about $4.1 \mathrm{~nm}$ and major volume fraction of these CdS nanoparticles is exhibiting radius within $0.6 \mathrm{~nm}$ to $8.3 \mathrm{~nm}$. The CdS nanoparticle size distribution cuves exhibit relative standard deviation of 34\% (approximately) for both the samples. The surface-to-volume ratio $(\mathrm{S} / \mathrm{V})$ was calculated from the distribution curve for each sample which lies about $0.09 \AA^{-1}$. The high surface-to-volume ratio together with size effects (quantum

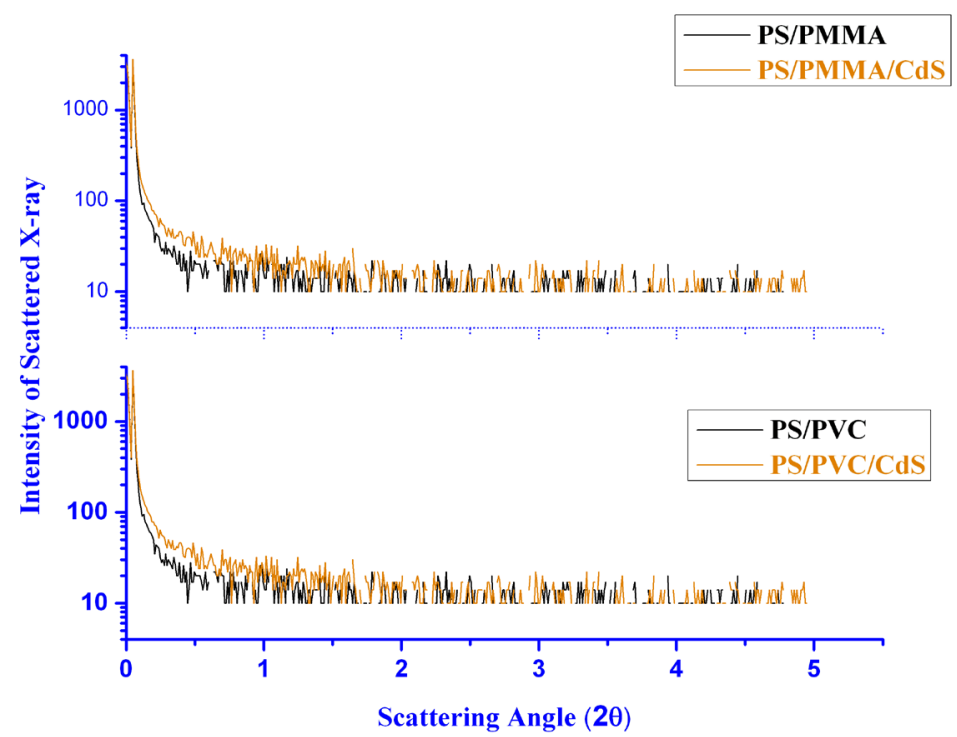

Figure 1. SAXS pattern of 50PS/50PMMA \& 50PS/50PMMA/CdS nanocomposites.

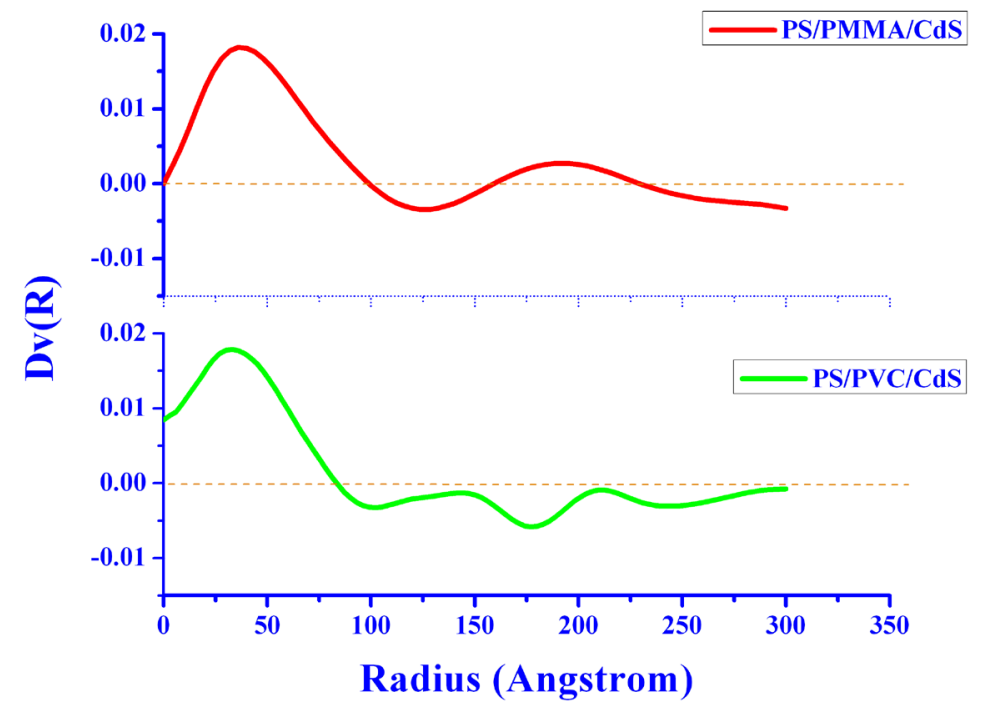

Figure 2. Particle size distribution curves for PS/PMMA/CdS and PS/PVC/CdS nanocomposites.

Table 1. Summary of particle size distribution curves analysis.

\begin{tabular}{cccccc}
\hline Sr. No. & Sample & Most frequent radius & Average radius & Relative standard deviation & Surface to volume ratio S/V \\
\hline 1 & PS/PMMA/CdS & $4.3 \mathrm{~nm}$ & $8.33 \mathrm{~nm}$ & $35.62 \%$ & $0.09213(1 / \mathrm{A})$ \\
2 & PS/PVC/CdS & $3.8 \mathrm{~nm}$ & $7.81 \mathrm{~nm}$ & $32.01 \%$ & $0.08712(1 / \mathrm{A})$ \\
\hline
\end{tabular}


effects) of nanoparticles is used to evaluate many size-dependent phenomena such as chemical, electronic, magnetic and mechanical properties of the prepared samples [8].

\section{Conclusions}

- The physical structure characterization of CdS nanoparticles dispersed in PS/PMMA and PS/PVC polymer blend matrices respectively using small angle X-ray scattering study reveal that the SAXS can illuminate the morphologies of respective polymer nanocomposites.

- The observed values of average particle size of CdS nanoparticles in both the nanocomposite samples lie within nano dimensions (i.e. below $100 \mathrm{~nm}$ ) and imply that the prepared samples exhibit their nanocomposite nature.

\section{References}

[1] Raji, P., Sanjeeviraja, C. and Ramachandran, K. (2005) Thermal and Structural Properties of Spray Pyrolysed CdS Thin Film. Bulletin Material Science, 28, 233-238. http://dx.doi.org/10.1007/BF02711253

[2] Kundu, S. and Liang, H. (2008) Photochemical Synthesis of Electrically Conductive CdS Nanowires on DNA Scaffolds. Advance Materials, 20, 826-831. http://dx.doi.org/10.1002/adma.200702162

[3] Hsu, Y.J., Lu, S.Y. and Lin, Y.F. (2008) Formation of Polycyanoacrylate-Silica Nanocomposites by Chemical Vapor Deposition of Cyanoacrylates on Aerogels. Chemistry of Materials, 20, 2854-2856. http://dx.doi.org/10.1021/cm7030703

[4] Mathur, V., Dixit, M., Rathore, K.S., Saxena, N.S. and Sharma, K. (2009) Morphological Effects on Mechanical Properties of Polystyrene-Polyvinylchloride Blends. Phase Transitions Volume, 82, 769-779. http://dx.doi.org/10.1080/01411590903445089

[5] Fekete, E., Foldes, E. and Pukanszky, B. (2005) Effect of Molecular Interactions on the Miscibility and Structure of Polymer Blends. Europian Polymer Journal, 41, 727-736. http://dx.doi.org/10.1016/j.eurpolymj.2004.10.038

[6] Wagner, M.H., Kheirandish, S., Koyama, K., Nishioka, A., Minegishi, A. and Takahashi, T. (2005) Modeling Strain Hardening of Polydisperse Polystyrene Melts by Molecular Stress Function Theory. Rheologica Acta, 44, $235-243$. http://dx.doi.org/10.1007/s00397-004-0402-7

[7] Boldyryeva, H., Umeda, N., Plaskin, O.A., Takeda, Y. and Kishimoto, N. (2005) High-Fluence Implantation of Negative Metal Ions into Polymers Surface Modification and Nanoparticle Formation. Surface and Coatings Technology, 196, 373-377. http://dx.doi.org/10.1016/j.surfcoat.2004.08.159

[8] Akbaril, B., Tavandashti, M.P. and Zandrahimi, M. (2011) Particle Size Characterization of Nanoparticles—A Practical Approach. Iranian Journal of Materials Science \& Engineering, 8, 48-56.

[9] Mathur, V., Rathore, K.S. and Sharma, K. (2013) Evaluation of Energy Band Gap, Thermal Conductivity, Phase Transition Temperature and Elastic Response of PS/CdS Semiconducting Optical Nanocomposite. World Journal of Nanoscience and Engineering, 2, 93-99. http://dx.doi.org/10.4236/wjnse.2013.33013

[10] Mathur, V., Dixit, M. and Sharma, K. (2014) Structural Characterization of PS, PVC and PS/PVC Polymeric Blend. SKIT Research Journal, An International Journal of Engineering, Science, Humanities and Management, 4, 76-77.

[11] Lindner, P. and Zemb, Th. (2002) Neutron, X-Rays and Light. Scattering Methods Applied to Soft Condensed Matter. Elsevier, Amsterdam. 
Scientific Research Publishing (SCIRP) is one of the largest Open Access journal publishers. It is currently publishing more than 200 open access, online, peer-reviewed journals covering a wide range of academic disciplines. SCIRP serves the worldwide academic communities and contributes to the progress and application of science with its publication.

Other selected journals from SCIRP are listed as below. Submit your manuscript to us via either submit@scirp.org or Online Submission Portal.
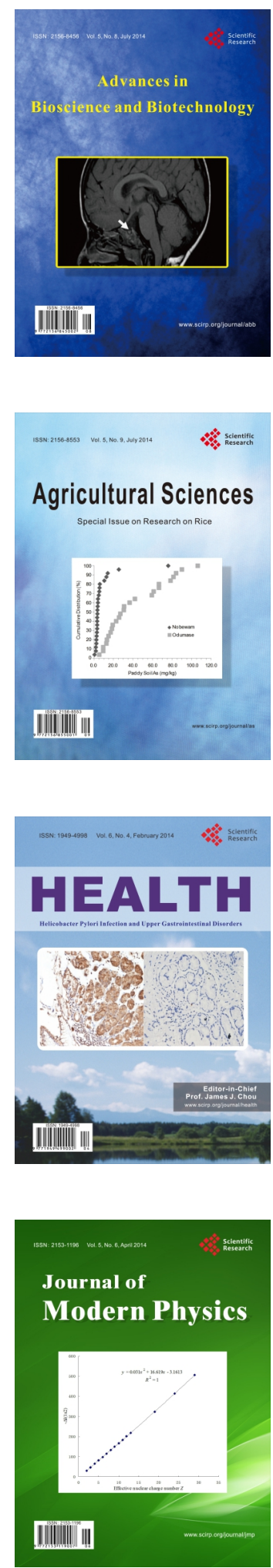
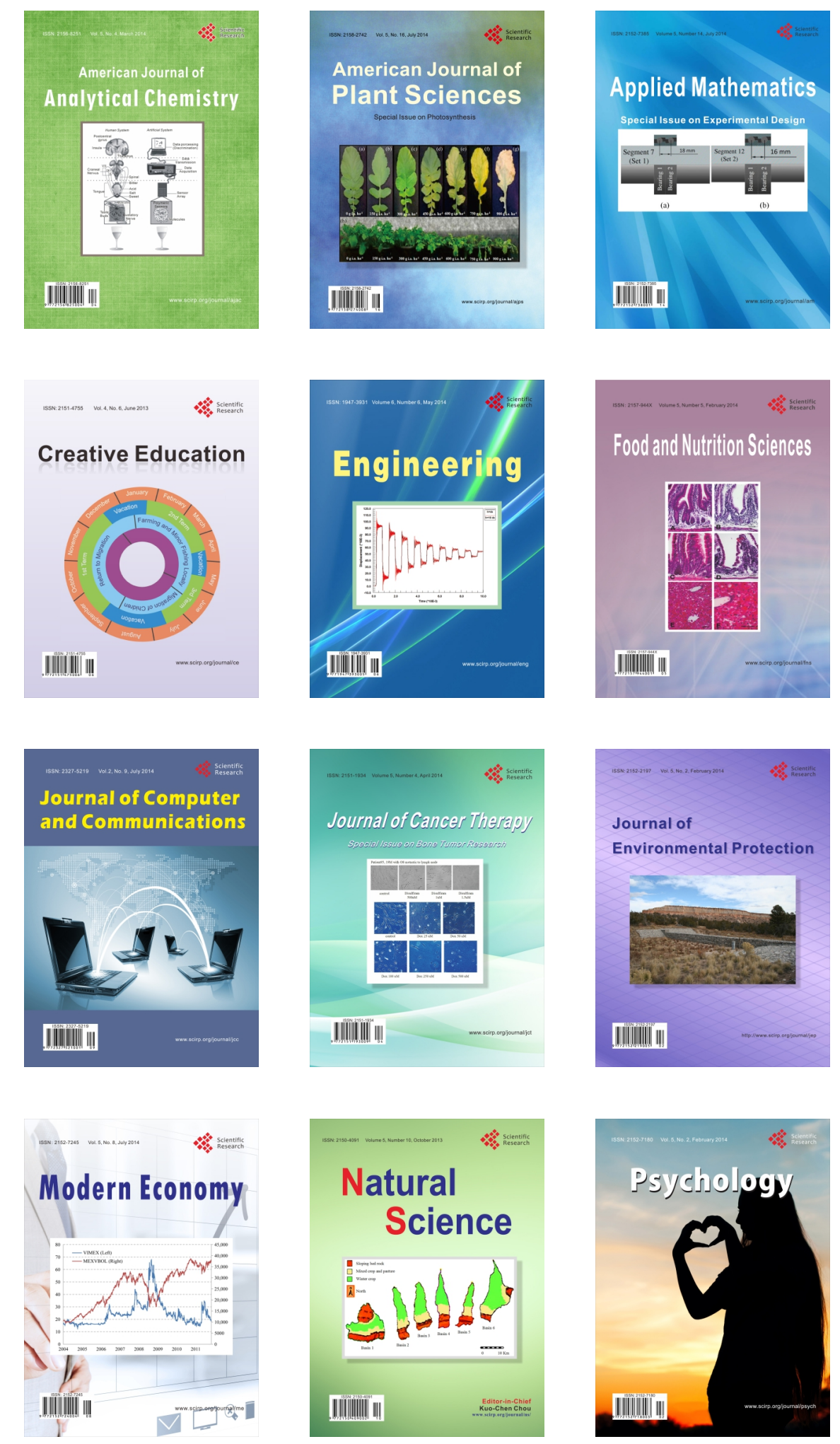